\title{
Tendências da alimentação contemporânea: percurso e elementos para uma agenda de pesquisa
}

RENATA MENASCHE

\section{Introdução}

É sabido que os significados da alimentação não são apreensíveis apenas a partir de indicadores nutricionais: o ato alimentar implica em valoração simbólica (Fischler 1979; 1993). Assim, ainda que inserida em rotina e aparente monotonia, a ingestão de alimentos não é ação neutra, revestindo-se de sentidos e valores, que se expressam em escolhas e práticas alimentares. Comer é sim necessidade de ordem biológica, mas é também fato econômico, histórico, social e cultural: a fome e a sede são formuladas e satisfeitas nesses termos (Millán 2002). Desse modo, o que se come, com quem se come, quando, como e onde se come são definidos pela cultura (Garine 1987; 2001).

Nos últimos anos, observamos a amplificação da presença da comida em programas de TV, publicações e mídias sociais; a disseminação de cursos - também universitários - de Gastronomia; a glamourização de $\operatorname{ch} f s$; a ascensão de movimentos sociais centrados em práticas de produção e consumo de alimentos (agroecologia, veganismo, Slow Food, entre outros); a implantação de políticas públicas de Segurança Alimentar e Nutricional; a multiplicação de produtos voltados às inúmeras restrições alimentares, que parecem atingir parcelas cada vez mais significativas da população; a difusão de espaços de oferta de produtos orgânicos/biológicos e a valorização de produtos locais, artesanais, tradicionais.

Comer é também ato político e é nesse quadro que novas questões têm permeado decisões de consumo alimentar, repercutindo em processos de produção e distribuição de alimentos, gerando tendências culinárias, transformando produtos e embalagens, incorporando inovações tecnológicas, criando novos mercados e orientando políticas públicas. Temas críticos de nossa época estão postos à mesa: comida é, 
entre outras coisas, consumo, direito humano, saúde, meio ambiente, direitos animais, patrimônio. E, ao tempo em que a alimentação tem, cada vez mais, presença em ampla gama de rodas de conversa, os estudos da sociedade já não a podem perceber como tema banal ou exótico. É assim que observamos sua ascensão ao estatuto de objeto legítimo de pesquisa, merecedor de atenção por um número crescente de investigadores/as, constituinte do que vem, nos últimos anos, consolidando-se como um vigoroso campo multidisciplinar, os Food Studies.

É nesse quadro e no processo de formulação de uma agenda de pesquisa voltada à reflexão sobre as tendências da alimentação contemporânea, particularmente no que se refere ao lugar dos alimentos locais, artesanais, tradicionais e aos apelos de ruralidade, naturalidade e saudabilidade, que este texto se propõe a revisitar algumas das pesquisas conduzidas, ao longo da última década, no âmbito do Grupo de Estudos e Pesquisas em Alimentação, Consumo e Cultura (Gepac).

Mas, antes disso, vale delinear um panorama acerca do tema proposto.

\section{Breves linhas sobre alimentação nas sociedades contemporâneas}

Cabe inicialmente ter em conta que o processo de globalização - a que estão associadas a industrialização e a circulação de alimentos em distâncias cada vez maiores - promove padronização e uniformização de produtos consumidos, de gostos e de comportamentos alimentares. No entanto, ao observar que mesmo grandes redes de fast food incluem em seus cardápios ingredientes e pratos pertencentes às culinárias locais ${ }^{1}$, podemos afirmar, com Canclini (1997), que a relação entre globalização e culturas locais pressupõe um movimento de homogeneização, mas não se restringe a ele: o global não pode ser entendido como substituto do local.

Em artigo em que abordam a culinária a partir de sua expressão escrita², Gomes e Barbosa (2004) assinalam a ocorrência, a partir do final do século XX, de um boom culinário e gastronômico, associando-o a um processo de valorização da arte culinária, então convertida em gastronomia. Esse movimento - que sucede aquele em que se dera, a partir da década de 1950, a intensificação da industrialização da alimentação - é caracterizado por uma maior segmentação de produtos, pratos e cozinhas, relacionada a mudanças ocorridas na sociedade e nas famílias, que indicam, por um lado, maior individualização no consumo alimentar e, por outro, uma ressignificação da cozinha, que passa a ser percebida como espaço de distinção e cenário em que se realiza a sociabilidade, uma vez que é nela que passam a ser recebidos os amigos.

Também o antropólogo espanhol Jesús Contreras (2005) identifica a ocorrência de uma "eclosão da gastronomia”, conferindo destaque a aspectos hedonistas, estéticos e criativos da comida e à valorização de produtos locais e/ou artesanais, relacionados a território e cultura específicos, produtos que,

1 A título de exemplo, percorrendo algumas das lojas de uma das mais conhecidas redes mundiais de fast-food, observa-se que água de coco e sobremesa à base de maracujá são itens presentes no cardápio de lojas brasileiras, enquanto que em Portugal pode-se pedir um caldo verde.

2 A "culinária de papel", analisada no estudo citado, compreendeu um banco de dados composto por 907 livros sobre o tema, publicados no Brasil entre os inícios dos séculos XX e XXI. 
como mostra Paxson (2012) em estudo sobre queijos artesanais realizado nos Estados Unidos, são vinculados a valores e sabores associados à boa comida.

É assim, e tendo presentes injunções entre comida e memória como discutidas por Mintz (2001; 2003), que podemos atribuir às transformações do comer decorrentes da globalização - marcadas por um movimento de homogeneização da alimentação -, o surgimento de uma "nostalgia" referente a práticas alimentares. Nas palavras de Contreras (2005: 138),

A "insipidez" de tantos alimentos oferecidos pela indústria agroalimentar provocaria lembranças mais ou menos mistificadas das "delícias" e "variedades" de ontem. Assim, desenvolve-se nos últimos anos uma consciência da erosão dos complexos alimentares animais e vegetais.

Partindo, nessa reflexão, de abordagens oferecidas pelos estudos da alimentação e do consumo, toma-se por contexto, por um lado, a identificação de uma ansiedade contemporânea em relação à alimentação e, por outro, um quadro em que podemos notar, na sociedade, um uso ideológico da diversidade - em que se dá valorização do local, artesanal, tradicional -, a expressão, nas classificações da alimentação operadas por consumidores urbanos, de um rural valorado positivamente, idealizado, em que são demandados alimentos, mas também paisagens, costumes, festas, história, turismo (Menasche, 2010; 2013).

A alimentação é, assim, também percebida como expressão de um imaginário sobre o rural, constituído especialmente por moradores de centros urbanos em suas práticas de consumo, mas também reveladora de diluições e redefinições de fronteiras entre campo e cidade - tal como manifestam as ambiguidades presentes em práticas produtivas e de consumo de variados segmentos de agricultores, ou ainda na circulação de alimentos que chegam por circuitos de sociabilidade a parentes que vivem na cidade -, assim como sinal diacrítico de identidades (étnicas, regionais) que congregam o rural como atributo. Daí pensar sobre as tendências da alimentação contemporânea a partir de fluxos entre campo e cidade.

\section{Percurso de pesquisas realizadas}

A constituição do Gepac data de 2006, inicialmente reunindo pesquisadores/as e estudantes vinculados/as ao Programa de Pós-Graduação em Desenvolvimento Rural da Universidade Federal do Rio Grande do Sul (PGDR/UFRGS), aos quais, a partir de 2008, somaram-se pesquisadores/as e estudantes de graduação e pós-graduação da Universidade Federal de Pelotas (UFPel). Apenas em 2018 o Gepac incorporaria consumo no nome, passando a designar-se Grupo de Estudos e Pesquisas em Alimentação, Consumo e Cultura.

Sua formação deu-se no contexto em que eram finalizadas as atividades do projeto de pesquisa $A$ multifuncionalidade da agricultura à mesa: hábitos alimentares e produção para autoconsumo; identidade e estratégias de reprodução social de familias rurais (CNPq 503566/03-09), cujos resultados seriam sistematizados no livro A agricultura familiar à mesa: saberes e práticas da alimentação no Vale do Ta- 
quari (Menasche 2007). Tal projeto fora conduzido, entre 2004 e 2006, por uma equipe multidisciplinar composta por docentes e discentes do curso de bacharelado em Desenvolvimento Rural e Gestão Agroindustrial da Universidade Estadual do Rio Grande do Sul (Uergs, Unidade de Encantado) e do Programa de Pós-Graduação em Desenvolvimento Rural da Universidade Federal do Rio Grande do Sul (PGDR/UFRGS), que buscou observar práticas da alimentação de famílias rurais e manifestações de sociabilidade a elas relacionadas. Foram então estudados contextos cotidianos e de festas comunitárias, tendo sido entrevistadas 48 famílias, de três distintas localidades rurais. As visitas a elas realizadas, para preenchimento de formulário que buscava identificar suas práticas de produção e consumo de alimentos, seriam oportunidades para "tomar um chimarrão ou provar o vinho da casa; experimentar um queijo, um bolinho frito ou uma cuca; olhar o livro de receitas; conhecer as ervas medicinais utilizadas pela família; ver a horta e as criações; comer frutas; observar a casa e a cozinha; escutar histórias" (Menasche 2007: 8).

A dissertação de Mariana Ramos (2007) ${ }^{3}$ - A “comida da roça” ontem e hoje: um estudo etnográfico dos saberes e práticas alimentares de agricultores de Maquiné (RS) -, cuja pesquisa foi realizada no litoral norte do Rio Grande do Sul, desenvolveu-se em interlocução com as discussões geradas no processo de sistematização dos dados obtidos na pesquisa conduzida no Vale do Taquari. Esse estudo destacou as mudanças ocorridas, ao longo de um período de três décadas - em que teve lugar o processo de modernização da agricultura -, nos saberes e práticas alimentares das famílias rurais estudadas, apontando a ocorrência de redução (em volume e diversidade) da produção voltada ao autoconsumo e aumento da participação no cardápio cotidiano de alimentos adquiridos no mercado. À comida da roça ou do gasto, classificada como comida boa, os/as interlocutores/as da pesquisa associaram atributos como força e pureza, enquanto consideravam fraca a comida da cidade. Ao etnografar duas festas locais, uma produzida para atrair moradores da cidade, outra dirigida aos próprios moradores da localidade rural, a autora explorou relações entre comida, identidade e sociabilidade, mostrando como a valorização, na primeira festa, do alimento "típico" - no caso, a polenta - era reveladora de percepções de fronteiras entre os espaços rural e urbano.

$\mathrm{Na}$ sequência das pesquisas realizadas no Vale do Taquari, anteriormente mencionadas, foram desenvolvidas, na mesma região, as dissertações de Josiane Wedig (2009) e Cândida Zanetti (2010) e, em outros contextos empíricos, a dissertação de Jone Mirasse (2010), a tese de Ana Maria Costa Beber (2012) e o TCC de Carmen Janaina Machado (2011), este já inserido na agenda de pesquisas Saberes e sabores da colônia, articulada, desde 2011, a partir dos projetos de pesquisa Cultura, patrimônio e segurança alimentar entre familias rurais: etnografias de casos significativos (CNPq 559565/2010-0), Saberes e sabores da colônia: modos de vida e patrimônio alimentar entre pomeranos no Brasil meridional (Fapergs

3 Serão mencionados apenas os trabalhos de conclusão de curso (TCCs), dissertações de mestrado, teses de doutorado e livros produzidos no âmbito do Gepac em temas diretamente associados à discussão aqui em tela e elaborados sob a orientação ou organização da autora deste artigo. Esses e demais trabalhos produzidos, bem como boa parte dos artigos deles decorrentes, são disponibilizados no sítio https://www.ufrgs.br/gepac/, no item "Produções". Vale ainda mencionar que, à exceção das pesquisas realizadas para a dissertação de Jone Mirasse (2010, Moçambique) e para a tese de Jaqueline Sgarbi Santos (2014, Minas Gerais e Rio Grande do Sul), bem como a realizada pela autora deste artigo durante sua estada, em 2018, como investigadora visitante junto ao Instituto de Ciências Sociais da Universidade de Lisboa (ICS/UL), todos os demais trabalhos citados tiveram contextos empíricos circunscritos ao Rio Grande do Sul. 
1018354/2010-6) e Saberes e sabores, objetos e imagens da colônia (Fapergs 2067-2551/13-0), cujos resultados compõem o livro Saberes e sabores da colônia: alimentação e cultura como abordagem para o estudo do rural (Menasche 2015), bem como um conjunto de produtos imagéticos, do qual fazem parte um CD-ROM interativo e um DVD que reúne 10 vídeos etnográficos ${ }^{4}$.

Assim como fizera Ramos (2007), em Sabores e saberes: hábitos e práticas alimentares entre familias rurais descendentes de imigrantes italianos na região do Vale do Taquari/RS, Zanetti (2010) conduziu a observação, sempre a partir das práticas da alimentação, às mudanças ocorridas na vida e trabalho de colonos de origem italiana, enquanto que o trabalho de Wedig (2009), Agricultoras e agricultores à mesa: um estudo sobre campesinato e gênero a partir da antropologia da alimentação, realizado em localidade constituída por colonos de origem alemã, fê-lo conferindo particular atenção às relações de gênero e geração. Para isso, sua etnografia, tomando como espaços de observação tanto rituais festivos e religiosos como o cotidiano das famílias estudadas, evidenciou classificações que, ao tempo em que ordenam suas práticas alimentares, organizam o lugar dos vários componentes na hierarquia familiar. $\mathrm{O}$ trabalho mostrou ser comum, entre os jovens da localidade estudada, permanecer residindo nas propriedades rurais familiares, mas dedicados a ocupações não agrícolas, contexto em que o campo é afirmado como local de moradia desejado, "por constituir-se em um ambiente mais tranquilo e menos violento do que a cidade, por fornecer alimentos considerados mais saborosos e saudáveis, por possibilitar cotidianamente a manutenção dos laços familiares e de amizade" (Wedig 2009: 66). Ainda com o olhar voltado à alimentação, a autora notou que, se bem é verdade que, tal como ocorre entre citadinos, possa ser observada entre os jovens rurais da localidade estudada uma idealização do rural, a valorização de alimentos associados a práticas tradicionais de produção e consumo sempre teve presença entre os agricultores e agricultoras ouvidos, ainda que - e de modo contraditório - coexistindo com uma sua faceta estigmatizada, gerada no processo de superestimação da alimentação industrializada, moderna.

Enquanto Ramos (2007) colocara em destaque a polenta como articuladora, a partir da perspectiva da cidade, de uma identidade rural, na etnografia Comida, simbolismo e identidade: um olhar sobre a constituição da italianidade nas colônias Maciel e São Manoel - Pelotas (RS), Machado (2011) analisou o protagonismo atribuído ao vinho - tema da festa da localidade rural estudada, à qual aflui público urbano - na valorização de um rural associado à italianidade. A autora mostra que, na medida em que as práticas alimentares referidas a essa italianidade são comuns a colonos de diferentes origens étnicas, ela pode ser entendida como expressão do que Seyferth (1994) concebeu como cultura camponesa compartilhada.

Tal como o trabalho de Wedig (2009), o de Mirasse (2010) - O consumo da batata doce de polpa alaranjada entre familias rurais do Nordeste de Moçambique: um estudo sobre percep̧̧óes de comida e Segurança Alimentar na provincia de Nampula, que partiu de inquietação decorrente da não adesão pela população à política pública que propunha a difusão da batata-doce de polpa alaranjada como instrumento

\footnotetext{
4 Esses projetos de pesquisa foram conduzidos a partir de parceria constituída entre Gepac, Laboratório de Estudos Agrários e Ambientais - LEAA/UFPel e Laboratório de Ensino, Pesquisa e Produção em Antropologia da Imagem e do Som - Leppais/UFPel, sendo que os produtos imagéticos associados à agenda de pesquisa Saberes e Sabores da Colônia foram elaborados sob a coordenação do Leppais. O acervo imagético produzido (fotos, ensaios fotográficos, vídeos), assim como outros produtos, está disponibilizado no sítio https:// wp.ufpel.edu.br/saberesesaboresdacolonia/.
} 
para combater a insegurança alimentar em regiões rurais de Moçambique - foi construído a partir da identificação das classificações êmicas de alimentos e pessoas. A etnografia mostrou que, ainda que eficaz sob uma perspectiva nutricional, tal alimento era objeto de rejeição cujas raízes remontam ao passado de colonização e escravidão, contexto de sofrimento associado à privação da liberdade, dissolução das famílias e escassez de alimentos, quando a batata-doce - de polpa branca, antecessora da de polpa alaranjada, esta resultante da pesquisa agropecuária - era o cultivo possível realizado por crianças cujos pais e mães haviam sido levados ao trabalho forçado em terras de colonizadores. Nativos, cativos e estrangeiros são, na região estudada, termos respectivamente associados às pessoas que pertencem à comunidade; às que têm nela suas raízes, mas que, ainda que provisoriamente, dela se afastaram, passando a viver na cidade; às que são de fora. Tais termos são, também respectivamente, associados à mandioca - alimento presente nos pratos tradicionais e no cotidiano da vida local -; à batata-doce de polpa branca; à batata-doce de polpa alaranjada. A essa classificação está relacionado um gradiente de confiabilidade, atributo não pertinente a estrangeiros, pessoas ou alimentos.

No trabalho de Costa Beber (2012), Turismo rural, modos de vida em mudança e percep̧̧̃oes do rural: um estudo a partir das práticas alimentares de familias rurais em contexto de interação com turistas, as mudanças ocorridas, também observadas a partir da alimentação, são analisadas sob a perspectiva do consumo, na interação de famílias rurais com turistas, citadinos. É nesse contexto que a comida nossa é diferenciada da comida turistica e da comida da cidade.

O consumo seria também orientador das pesquisas realizadas para as dissertações de Carolina Rodrigues (2012), Danielle Wille (2014), Camila Ramos (2015) e Nicole Benemann (2017), assim como para os TCCs de Lidiane Hirdes (2016) e Tatiana Elesbão (2018). E estaria presente nos trabalhos que, estudando queijos artesanais, debruçaram-se sobre a temática dos produtos tradicionais: a dissertação de Evander Krone (2009) e as teses de Fabiana Thomé da Cruz (2012) e Jaqueline Sgarbi Santos (2014). Mas antes de apresentá-los, cabe completar o quadro dos estudos que, juntamente ao de Machado (2011), antes mencionado, integraram a agenda de pesquisas Saberes e sabores da colônia, consolidando a perspectiva que propõe o estudo das injunções entre alimentação e cultura como abordagem para o estudo do rural: o TCC de Maurício Schneider (2013), a tese de Teila Ceolin (2016) e as dissertações de Evander Krone (2014), Carmen Janaina Machado (2014) e Raquel Rau (2016), sendo que os três últimos aportaram problematizações a políticas públicas em diferentes áreas, a saber: Patrimônio, Reforma Agrária e Segurança Alimentar e Nutricional.

Enquanto o estudo de Schneider (2013), Entre a agroecologia e a fumicultura: uma etnografia sobre trabalho na terra, cosmologias epertencimentos entre camponeses pomeranos, trouxe à tona a produção agroecológica, a partir de etnografia que possibilitou perceber a comida como mediadora do pertencimento à comunidade da família rural que se distingue das demais ao fazer agricultura sem o emprego de agroquímicos 5 , o de Krone (2014), Comida, memória e patrimônio cultural: a construção da pomeranei-

5 Nas festas comunitárias e casamentos da localidade, o casal da família estudada, agricultores agroecológicos, é responsável pela preparação do caldo pomerano (ele) - produzido com carne, feijão e temperos - e da sopa de galinha (ela), pratos tradicionais de presença obrigatória nas festas realizadas entre colonos pomeranos. 
dade no extremo sul do Brasil, conduziu a atenção às disjunções entre, por um lado, os sentidos acionados pelas políticas públicas locais de patrimonialização da cultura pomerana e projetos delas decorrentes e, por outro, os vividos em comunidades rurais constituídas por colonos pomeranos. $\mathrm{O}$ autor mostrou que as ações de valorização do patrimônio cultural pomerano remetem a formas tradicionais do "ser pomerano", convertendo - a partir de uma visão preservacionista do passado, marcada por nostalgia - em atrativo turístico as famílias rurais e sua cultura alimentar.

Também realizado entre colonos pomeranos, o trabalho de Ceolin (2016), Sistema de cuidado à saúde entre famílias rurais ao sul do Rio Grande do Sul, buscou compreender o sistema de cuidado à saúde - em que estão inseridas as práticas alimentares - das famílias rurais do município de Canguçu estudadas, ao tempo que o de Rau (2016), Modos de comer, modos de viver: um olhar sobre o Programa Nacional de Alimentação Escolar e suas interfaces com a cultura e o desenvolvimento local a partir de famílias rurais pomeranas de São Lourenço do Sul, realizado junto a uma escola municipal e localidades de seu entorno, analisou concepções e práticas alimentares para conduzir a atenção às interfaces entre o programa de alimentação escolar e os hábitos alimentares locais, identificando-os e evidenciando as transformações pelas quais têm passado os modos de comer e de viver das famílias rurais estudadas.

Já a etnografia de Machado (2014), "Aqui até o arado é diferente": transformaçôes no fazer agricultura e em hábitos alimentares entre familias assentadas - um estudo realizado no Assentamento União, Rio Grande do Sul, tomou por contexto empírico um assentamento de reforma agrária e conduziu o olhar para as trajetórias de pessoas e objetos em deslocamento para contextos naturais e culturais distintos daqueles de sua origem, destacando as mudanças ocorridas nas práticas agrícolas e da alimentação de famílias rurais assentadas. Nesse trabalho, assim como no de Sgarbi Santos (2014) - a ser comentado adiante -, objetos e técnicas referentes ao universo da alimentação dos contextos estudados ganharam protagonismo nas narrativas condutoras da análise, perspectiva que antes se insinuara nos estudos de Zanetti (2010) e de Costa Beber (2012) e que se aprofundaria na etnografia Histórias de cozinha: uma etnografia gastronômica, que, realizada por Benemann (2017) em ambiente de cozinhas profissionais de Pelotas, apontou para uma antropologia do cozinhar.

O estudo de Rodrigues (2012), Mulheres negras em movimento: trajetórias militantes, negritude e comida no Sul do Rio Grande do Sul, que, dedicado a evidenciar o processo de construção da negritude de um grupo de mulheres negras de São Lourenço do Sul e tendo presente a significância de objetos e práticas nessa construção, conferiu especial atenção a comidas e pratos produzidos por elas - com destaque ao "vatapá à moda gaúcha” e ao quibebe -, oferecidos ao público em eventos em que a identidade do grupo é afirmada e, dessa forma, operando o olhar sobre a comida e o consumo como abordagem para apreensão do processo social em análise, tal como o fazem os trabalhos congregados na agenda de pesquisa Saberes e sabores da colônia.

As pesquisas realizadas por Hirdes (2016), O caderninho de receitas está nas nuvens: um estudo on e off-line sobre práticas alimentares veganas, e Elesbão (2018), Intolerância à lactose não é frescura: um estudo antropológico sobre restriçóes alimentares, elegeram universos empíricos associados à figura do consumidor puro (Cazes-Valette, 1997), distanciado dos processos de produção dos alimentos, mas, 
dadas as especificidades dos grupos estudados, nem por isso menos permeáveis a valorações referentes a saudabilidade, naturalidade, ruralidade.

Com o foco em um espaço de fronteira entre a produção e o consumo de alimentos, o estudo de Ramos (2015), Frutas, legumes e verduras nas feiras-livres de Pelotas e sua contribuição na Segurança Alimentar e Nutricional, que traçou uma caracterização das feiras de Pelotas, buscou apreender, sob o ponto de vista dos/as feirantes, a valoração dos alimentos por eles/as comercializados. Já a pesquisa de Wille (2014), No supermercado, "o segredo é o carinho": um estudo sobre consumo a partir do rural, caseiro e natural em embalagens de alimentos, foi, também em Pelotas, realizada a partir de outro espaço de comercialização de alimentos, supermercados, conduzindo o olhar, por um lado, a embalagens de alimentos industrializados e correspondentes estratégias comunicacionais utilizadas pelas empresas e, por outro, a critérios de seleção e percepções de qualidade dos consumidores em relação a esses alimentos.

Fechando o quadro, temos que dentre os trabalhos realizados no âmbito do Gepac no período delimitado, três dedicaram-se a apreender dinâmicas associadas a produtos locais, artesanais, tradicionais, estudando especificamente queijos produzidos à base de leite cru. A dissertação de Krone (2009), Identidade e cultura nos Campos de Cima da Serra (RS): práticas, saberes e modos de vida de pecuaristas familiares produtores do Queijo Serrano - que, vale mencionar, realizou-se em continuidade à pesquisa de seu TCC (Krone 2006), Práticas e saberes em movimento: a história da produção artesanal do Queijo Serrano entre pecuaristas familiares do municipio de Bom Jesus $(R S)$-, iluminou aspectos referentes à produção artesanal do queijo estudado, associados à organização do processo de trabalho, ao saber-fazer tradicional, às práticas de sociabilidade, costumes e tradições inseridos no modo de vida das famílias rurais produtoras. Também tomando por objeto de estudo o queijo serrano, o trabalho de Cruz (2012), Produtores, consumidores e valorização de produtos tradicionais: um estudo sobre qualidade de alimentos a partir do caso do Queijo Serrano dos Campos de Cima da Serra - RS, aportou ao apreender parâmetros locais de classificação que remetem à qualidade do queijo costumeiramente produzido, distintos daqueles prescritos pela legislação sanitária, enquanto que o estudo de Sgarbi Santos (2014), Dilemas e desafios na valorização de produtos alimentares tradicionais no Brasil: um estudo a partir do Queijo do Serro, em Minas Gerais, e do Queijo Serrano, no Rio Grande do Sul, conduziu o olhar para as políticas de valorização de produtos alimentares tradicionais, buscando observar como a implantação de alguns de seus instrumentos - a saber, indicações geográficas e registro de bens culturais de natureza imaterial - tem agido na transformação de sistemas produtivos e modos de vida associados nos contextos estudados.

\section{Elementos para uma agenda de pesquisa}

O percurso de pesquisas realizadas e o acúmulo teórico-metodológico no tema, dados a vislumbrar anteriormente, confluem em elementos e questões que delineiam uma agenda de pesquisa, em que - pensando a partir de fluxos entre campo e cidade, atravessados por distintas concepções de qualidade referentes à comida - se apresenta como desafio a apreensão das tendências da alimentação contemporânea. 


\section{Produtores como consumidores}

Toma-se aqui como ponto de partida para problematizar a questão a manifestação de Seu Artur, agricultor de Maquiné, município situado no litoral norte do Rio Grande do Sul, interlocutor de Ramos (2007: 90): “o porco light... é o que o pessoal mais quer, porque não tem colesterol”. Sua fala é indicadora de contato com o discurso medicalizado sobre alimentação, associado ao que considera a preferência dos consumidores urbanos. No entanto, a carne suína que Seu Artur e família apreciam não é a do porco light, mas a do porco da roça, de raça rústica, que produz mais banha do que as raças comumente difundidas no âmbito da indústria agroalimentar. É esse tipo de animal o criado para o autoconsumo da família, mas é também esse porco, da roça, o oferecido aos visitantes da cidade que chegam à localidade para, a cada ano, participar da Festa da Polenta.

$\mathrm{Na}$ relação com a comida, ainda que pouco se diga a respeito, agricultores não apenas produzem os alimentos. Pensando nos produtores enquanto consumidores, o que para eles/as é comer bem? Como suas concepções são permeadas, por um lado, pelo discurso medicalizado sobre a alimentação e correspondente apelo à saudabilidade e, por outro, por um processo de idealização do rural e valorização - a partir do consumo, realizado majoritariamente em espaços urbanos - de produtos considerados tradicionais?

\section{Produtos locais, artesanais, tradicionais: normatização, confiança e resistência}

Como evidenciado na literatura - e também em pesquisas referentes a queijos artesanais realizadas no âmbito do Gepac, antes mencionadas -, os parâmetros de qualidade que informam a normatização de produtos alimentares são estabelecidos a partir de contextos de produção industrial, orientando-se por uma perspectiva higienista e privilegiando instalações e equipamentos em detrimento de processos. É nesse quadro que produtos locais, artesanais, tradicionais são comumente considerados inadequados pela legislação sanitária, sendo colocados sob o risco de apreensão ${ }^{6}$.

Já nos contextos em que são elaborados esses produtos, as percepções acerca de sua qualidade são pautadas em relações de confiança e na reputação (Bailey 1971) dos produtores e, desse modo, conformadas localmente, a partir de parâmetros socialmente construídos. Nessas circunstâncias, confiança e reputação dos produtores apresentam-se como mecanismos de validação social da qualidade dos alimentos, sobrepondo-se mesmo àqueles estabelecidos a partir dos instrumentos de normatização do Estado, conformando algo como um sistema informal de certificação da qualidade. É esse o contexto em que, ainda que em conflito com a normatização vigente, as práticas tradicionais de produção têm sua legitimidade afirmada, dando base para - astúcias dos fracos (Certeau 2012) - adaptações realizadas em utensílios empregados no fabrico desses produtos, a exemplo do tacho, que, na região de Pelotas,

6 Ainda que constitutivo de ameaça cotidiana para famílias produtoras, o problema ganhou visibilidade a partir de episódio recente protagonizado por Roberta Sudbrack, reconhecida chef, transcorrido em festival musical realizado no Rio de Janeiro, o Rock in Rio (edição 2017). Para saber mais a respeito, ver reportagem de Roncato (2017). 
aparenta ser todo em inox e cuja parte interna inferior - que fica coberta por doce e, assim, invisível ao fiscal - é de cobre, material proibido.

\section{Rural idealizado, comida desejada}

Partindo do contexto - discutido na literatura e em vários dos trabalhos realizados no âmbito do Gepac, antes mencionados - em que, na alimentação contemporânea, estão presentes apelos de ruralidade, naturalidade e saudabilidade, apresentam-se diferentes formas de sua manifestação, associadas ou não à valorização de produtos locais, artesanais, tradicionais.

Colocam-se, assim, como campos passíveis de observação, variados espaços de comercialização e consumo de alimentos - supermercados, mercados, feiras, restaurantes -, bem como veículos de publicidade e comunicação referentes à alimentação, aí inclusas não apenas embalagens, mas também a miríade de blogs dedicados à comida.

\section{Desperdício alimentar e seus sentidos}

No Brasil, o debate em torno do desperdício alimentar foi, em 2017, amplificado a partir de polêmica lei que instituiu em São Paulo a Política Municipal de Erradicação da Fome e de Promoção da Função Social dos Alimentos. Ao declarar que "pobre não tem hábito alimentar, pobre tem fome", o prefeito daquela cidade pretendeu justificar que, ao tempo em que combate o desperdício de alimentos, a farinata - ração humana composta por alimentos com prazo de vencimento próximo da validade ou fora do padrão de comercialização em supermercados - fosse utilizada na rede escolar e incluída em cestas básicas distribuídas à população carente.

Essa iniciativa se coloca como parceira do programa da Organização das Nações Unidas para a Alimentação e a Agricultura (FAO) dirigido à redução das perdas e do desperdício alimentar, o Save Food, que, por sua vez, convidara a cooperativa de consumo portuguesa Fruta Feia a somar-se a ele.

Criado em 2013, atualmente o Fruta Feia articula mais de 3.700 consumidores associados, evitando que semanalmente sejam destinadas ao lixo cerca de 10 toneladas de frutas e hortaliças, produzidas por aproximadamente 150 famílias agricultoras. Contrapondo-se a padrões estéticos impostos pelo sistema agroalimentar e a seus valores, o Fruta Feia constitui-se a partir de princípios que, entendendo em perspectiva solidária cidade e campo, consumidores e produtores, propugnam que "gente bonita come fruta feia" e "gente bonita produz fruta feia".

Em um contexto em que o Brasil está prestes a retornar ao Mapa da Fome ${ }^{7}$ e em que se multiplicam propostas de combate ao desperdício alimentar, orientadas por concepções as mais diversas, este é certamente um tema que merece aprofundamento a partir da pesquisa antropológica.

7 O Mapa da Fome, da Organização das Nações Unidas (ONU), reúne os países que têm mais de 5\% da população ingerindo menos calorias do que o recomendável. Ver: https://www.pragmatismopolitico.com.br/2018/03/retorno-do-brasil-ao-mapa-da-fome.html. 
Renata Menasche é doutora em Antropologia Social e professora do Programa de Pós-Graduação em Antropologia da UFPel e do Programa de Pós-Graduação em Desenvolvimento Rural da UFRGS. É bolsista PQ2 do CNPq.

\section{REFERÊNCIAS BIBLIOGRÁFICAS}

BAILEY, Frederick George. 1971. Gifts and Poison. Oxford: Blackwell.

BEBER, Ana Maria Costa. 2012. Turismo Rural, Modos de Vida em Mudança e Percep̧ões do Rural: um Estudo a partir das Práticas Alimentares de Famílias Rurais em Contexto de Interação com Turistas. 261f. Tese (Doutorado em Desenvolvimento Rural), Universidade Federal do Rio Grande do Sul, Porto Alegre.

BENEMANN, Nicole Weber. 2017. Histórias de Cozinha: uma Etnografia Gastronômica. Dissertação (Mestrado em Antropologia), Universidade Federal de Pelotas, Pelotas.

CANCLINI, Néstor García. 1997. Consumidores e Cidadãos: Conflitos Multiculturais da Globalização. Rio de Janeiro: Ed. UFRJ.

CAZES-VALETTE, Geneviève. 1997. "La Vache Folle". Internationale de limaginaire: Nouvelle Série, $7: 205-233$.

CEOLIN, Teila. 2016. Sistema de Cuidado à Saúde entre Familias Rurais ao Sul do Rio Grande do Sul. Tese (Doutorado em Enfermagem), Universidade Federal de Pelotas, Pelotas.

CERTEAU, Michel de, 2012. A Invenção do Cotidiano, v. 1. Artes de Fazer. Petrópolis: Vozes. CONTRERAS HERNÁNDEZ, Jesús. 2005. "Patrimônio e Globalização: o Caso das Culturas Alimentares”. In: A.M. Canesqui; R.W.D. Garcia (org.), Antropologia e Nutrição: um Diálogo Possível. Rio de Janeiro: Fiocruz. pp. 129-145.

CRUZ, Fabiana Thomé da. 2012. Produtores, Consumidores e Valorização de Produtos Tradicionais: um Estudo sobre Qualidade de Alimentos a partir do Caso do Queijo Serrano dos Campos de Cima da Serra - RS. Tese (Doutorado em Desenvolvimento Rural), Universidade Federal do Rio Grande do Sul, Porto Alegre.

ELESBÃO, Tatiana Neis. 2018. Intolerância à Lactose não é Frescura: um Estudo Antropológico sobre

Restrições Alimentares. Trabalho de Conclusão de Curso (Graduação em Antropologia), Universidade Federal de Pelotas, Pelotas.

FISCHLER, Claude. 1979. "Présentation". Communications, 31: 1-3.

FISCHLER, Claude. 1993. L'homnivore: le Goût, la Cuisine et le Corps. Paris: Odile Jacob.

GARINE, Igor de. 1987. "Alimentação, Culturas e Sociedades". O Correio da Unesco, 15(7): 4-7.

GARINE, Igor de. 2001. "Views about Food Prejudice and Stereotypes”. Social Science Information, 40(3): 487-507.

GOMES, Laura Graziela; BARBOSA, Livia. 2004. “Culinária de Papel”. Estudos Históricos, 1(33): 3-23.

HIRDES, Lidiane da Silva. 2016. O Caderninho de Receitas Está nas Nuvens: um Estudo On e Off-line 
Sobre Práticas Alimentares Veganas. Trabalho de Conclusão de Curso (Graduação em Antropologia), Universidade Federal de Pelotas, Pelotas.

KRONE, Evander Eloí. 2006. Práticas e Saberes em Movimento: a História da Produção Artesanal do Queijo Serrano entre Pecuaristas Familiares do Município de Bom Jesus (RS). Trabalho de Conclusão de Curso (Graduação em Desenvolvimento Rural e Gestão Agroindustrial), Universidade Estadual do Rio Grande do Sul, Encantado.

KRONE, Evander Eloí. 2009. Identidade e Cultura nos Campos de Cima da Serra (RS): Práticas, Saberes e Modos de Vida de Pecuaristas FamiliaresProdutores do Queijo Serrano. Dissertação (Mestrado em Desenvolvimento Rural), Universidade Federal do Rio Grande do Sul, Porto Alegre.

KRONE, Evander Eloí. 2014. Comida, Memória e Patrimônio Cultural: a Construção da Pomeraneidade no Extremo Sul do Brasil. Dissertação (Mestrado em Antropologia), Universidade Federal de Pelotas, Pelotas.

MACHADO, Carmen Janaina Batista. 2011. Comida, Simbolismo e Identidade: um Olhar sobre a Constituição da Italianidade nas Colônias Maciel e São Manoel - Pelotas (RS). Trabalho de Conclusão de Curso (Graduação em Geografia), Universidade Federal de Pelotas, Pelotas.

MACHADO, Carmen Janaina Batista. 2014. “Aqui até o Arado é Diferente”: Transformações no Fazer Agricultura e em Hábitos Alimentares entre Famílias Assentadas - um Estudo Realizado no Assentamento União, Rio Grande do Sul. Dissertação (Mestrado em Desenvolvimento Rural), Universidade Federal do Rio Grande do Sul, Porto Alegre.

MENASCHE, Renata (org.). 2007. A Agricultura Familiar à Mesa: Saberes e Práticas da Alimentação no Vale do Taquari. Porto Alegre: Ed. UFRGS.

MENASCHE, Renata. 2010. “Campo e Cidade, Comida e Imaginário: Percepções do Rural à Mesa”. Ruris, 3(2): 195-218.

MENASCHE, Renata. 2013. "Cuando la Comida se Convierte en Patrimonio: Puntualizando la Discusión”. In: J.L.M. Calderón (org.), Patrimonio Inmaterial, Museos y Sociedad. Balances y Perspectivas de Futuro. Madrid: Ministerio de Educación, Cultura y Deporte de España. pp. 180-187.

MENASCHE, Renata (org.). 2015. Saberes e Sabores da Colônia: Alimentação e Cultura como Abordagem para o Estudo do Rural. Porto Alegre: Ed. UFRGS.

MILLÁN, Amado. 2002. "Malo para Comer, Bueno para Pensar: Crisis en la Cadena Socioalimentaria”. In: M. Gracia Arnaiz (coord.). Somos lo que Comemos: Estudios de Alimentación y Cultura en España. Barcelona: Ariel. pp. 277-296.

MINTZ, Sidney. 2001. "Comida e Antropologia: uma Breve Revisão”. Revista Brasileira de Ciências Sociais, 16(47):31-41.

MINTZ, Sidney. 2003. "Remembrance of Repasts: an Anthropology of Food and Memory”. American Ethnologist, 30(3): 474-475.

MIRASSE, Jone Januário. 2010. O Consumo da Batata Doce de Polpa Alaranjada entre Famílias Rurais do Nordeste de Moçambique: um Estudo sobre Percepções de Comida e Segurança Alimentar na Província de Nampula. Dissertação (Mestrado em Desenvolvimento Rural), Universidade Federal do Rio Grande do Sul, Porto Alegre. 
PAXSON, Heather. 2012. The Life of Cheese: Crafting Food and Value in America. Berkeley: University of California Press.

RAMOS, Camila Irigonhé. 2015. Frutas, Legumes e Verduras nas Feiras-Livres de Pelotas e sua Contribuição na Segurança Alimentar e Nutricional. Dissertação (Mestrado em Nutrição e Alimentos, Universidade Federal de Pelotas.

RAMOS, Mariana Oliveira. 2007. A “Comida da Roça” Ontem e Hoje: um Estudo Etnográfico dos Saberes e Práticas Alimentares de Agricultores de Maquiné (RS). Dissertação (Mestrado em Desenvolvimento Rural), Universidade Federal do Rio Grande do Sul.

RAU, Raquel. 2016. Modos de Comer, Modos de Viver: um Olhar sobre o Programa Nacional de Alimentação Escolar e suas Interfaces com a Cultura e o Desenvolvimento Local a partir de Famílias Rurais Pomeranas de São Lourenço do Sul. Dissertação (Mestrado em Desenvolvimento Rural), Universidade Federal do Rio Grande do Sul, Porto Alegre.

RODRIGUES, Carolina Vergara. 2012. Mulheres Negras em Movimento: Trajetórias Militantes, Negritude e Comida no Sul do Rio Grande do Sul. Dissertação (Mestrado em Ciências Sociais), Universidade Federal de Pelotas.

RONCATO, Murilo. 2017. "Como a Comida Descartada no Rock in Rio Pôs as Normas de Controle Alimentar em Debate”. Nexo. Disponível em: https://www.nexojornal.com.br/expresso/2017/09/18/ Como-a-comida-descartada-no-Rock-in-Rio-p\%C3\%B4s-as-normas-de-controle-alimentar-em-debate. Acesso em: 29 jul 2018.

SCHNEIDER, Maurício Dias. 2013. Entre a Agroecologia e a Fumicultura: uma Etnografia sobre Trabalho na Terra, Cosmologias e Pertencimentos entre Camponeses Pomeranos. Trabalho de Conclusão de Curso (Graduação em Antropologia), Universidade Federal de Pelotas, Pelotas.

SEYFERTH, Giralda. 1994. "A Identidade Teuto-Brasileira numa Perspectiva Histórica”. In: MAUCH, Cláudia; VASCONCELLOS, Naira (org.), Os Alemães no Sul do Brasil. Canoas: ULBRA. pp. 11-28. SGARBI SANTOS, Jaqueline. 2014. Dilemas e Desafios na Valorização de Produtos Alimentares Tradicionais no Brasil: um Estudo a partir do Queijo do Serro, em Minas Gerais, e do Queijo Serrano, no Rio Grande do Sul. Tese (Doutorado em Agronomia), Universidade Federal de Pelotas.

WEDIG, Josiane Carine. 2009. Agricultoras e Agricultores à Mesa: um Estudo sobre Campesinato e Gênero a partir da Antropologia da Alimentação. Dissertação (Mestrado em Desenvolvimento Rural), Universidade Federal do Rio Grande do Sul.

WILLE, Danielle Neugebauer. 2014. No Supermercado, "o Segredo éo Carinho”: um Estudo sobre Consumo a partir do Rural, Caseiro e Natural em Embalagens de Alimentos. Dissertação (Mestrado em Ciências Sociais), Universidade Federal de Pelotas.

ZANETTI, Cândida. 2010. Sabores e Saberes: Hábitos e Práticas Alimentares entre Famílias Rurais Descendentes de Imigrantes Italianos na Região do Vale do Taquari/RS. Dissertação (Mestrado em Desenvolvimento Rural), Universidade Federal do Rio Grande do Sul, Porto Alegre. 


\section{TENDÊNCIAS DA ALIMENTAÇÃo CONTEMPORÂNEA: PERCURSO E ELEMENTOS \\ PARA UMA AGENDA DE PESQUisa}

Resumo: Em um quadro em que o tema alimentação vem tendo sua presença amplificada em diferentes espaços sociais - também na academia, com a consolidação dos Food Studies - e no processo de formulação de uma agenda de pesquisa voltada à reflexão sobre as tendências da alimentação contemporânea, particularmente no que se refere ao lugar dos alimentos locais, artesanais, tradicionais e aos apelos de ruralidade, naturalidade e saudabilidade, este texto propõe-se a revisitar algumas das pesquisas conduzidas, ao longo da última década, no âmbito do Grupo de Estudos e Pesquisas em Alimentação, Consumo e Cultura (Gepac).

Palavras-chave: antropologia da alimentação, cultura alimentar, relações cidade-campo, consumo

\section{CONTEMPORARY FOOD TRENDS: PATHS AND ELEMENTS FOR A RESEARCH AGENDA}

Abstract: In a scenario in which food has been gaining space in many different social arenas - in addition to the academia, with the consolidation of Food Studies - and in the process of developing a research agenda focused on reflecting about contemporary food trends, particularly with regard to the role of local, artisan and traditional foods and to the calls of rurality, naturalness and wholesomeness, this text intends to review some researches that have been carried out in the last decade, within the scope of the Research \& Study Group on Food, Consumption and Culture (Gepac).

Keywords: food anthropology, food culture, city-country relationships, consumption

RECEBIDO: $12 / 02 / 2019$

APROVADO: 02/04/2019 